\title{
DIMENSI METRIK LOKAL PADA GRAF ANTIPRISMA DAN GRAF SUN
}

\author{
${ }^{1}$ Silfiatul Khoiriah, ${ }^{2}$ Tri Atmojo Kusmayadi \\ ${ }^{1,2}$ Universitas Sebelas Maret Surakarta
}

\begin{abstract}
For example $\mathrm{G}$ is a connected and nontrivial graph. The distance between two vertices $u$ and $v$ in $G$ is the shortest path length between vertex $u$ and $v$ which is denoted by $\mathrm{d}(\mathrm{u}, \mathrm{v})$. For an ordered set of $\boldsymbol{W}=\left\{\boldsymbol{w}_{1}, \boldsymbol{w}_{2}, \ldots, \boldsymbol{w}_{\boldsymbol{n}}\right\}$ of $\mathrm{n}$ vertex and $\mathrm{v}$ is a vertex in $\mathrm{G}$, then the representation of vertex $\mathrm{v}$ to $\mathrm{W}$ is an ordered pair $\boldsymbol{r}(\boldsymbol{v} \mid \boldsymbol{W})=$ $\left(\boldsymbol{d}\left(\boldsymbol{v}, \boldsymbol{w}_{\mathbf{1}}\right), \boldsymbol{d}\left(\boldsymbol{v}, \boldsymbol{w}_{\mathbf{2}}\right), \ldots, \boldsymbol{d}\left(\boldsymbol{v}, \boldsymbol{w}_{\boldsymbol{n}}\right)\right)$. Set $\mathrm{W}$ is called as local distinguishing if $\boldsymbol{r}(\boldsymbol{u} \mid \boldsymbol{W}) \neq \boldsymbol{r}(\boldsymbol{v} \mid \boldsymbol{W})$ for each pair of vertex $\mathrm{u}$ and $\mathrm{v}$ is adjacent to G. Local distinguishing set $\mathrm{W}$ with minimum cardinality is called as local metric base and the number of vertex on the local metric base of graph $G$ is called as local metric dimension which is denoted by $\operatorname{dim}_{l}(\boldsymbol{G})$. In this study, the local metric dimension is determined on antiprism An graph and sun Sn graph. The results reveal that local metric dimension of antiprism graph is $\operatorname{dim}_{l}\left(\boldsymbol{A}_{n}\right)=\mathbf{3}$ for $\boldsymbol{n} \geq \mathbf{3}$. Local metric dimension of sun graph is $\operatorname{dim}_{l}\left(\boldsymbol{S}_{n}\right)=\mathbf{1}$ for even $\mathrm{n}$ and $\operatorname{dim}_{l}\left(\boldsymbol{S}_{n}\right)=\mathbf{2}$ for odd $\mathrm{n}$.

Keywords: local metric dimension, antiprism graph, sun graph, local distinguishing set.
\end{abstract}

\section{PENDAHULUAN}

Teori graf adalah salah satu cabang ilmu matematika yang mempelajari mengenai terminologi, jenis, dan sifat graf. Menurut Chartrand dan Lesniak, suatu graf $G$ adalah himpunan tak kosong berhingga $V(G)=\left\{v_{1}, v_{2}, \ldots, v_{n}\right\}$ yang disebut himpunan vertex dan $E(G)=\left\{e_{1}, e_{2}, \ldots, e_{n}\right\}$ merupakan himpunan pasangan tidak berurutan dari anggota-anggota $V$ yang disebut edge. Vertex merupakanrepresentasi dari titik dan edge merupakan representasi dari garis. Teori grafdalam kegunaannya dapat diterapkan untuk menggambarkan berbagai macamstruktur yang ada dengan tujuan sebagai visualisasi objek agar menjadi mudahuntuk dipahami, seperti pada jaringan komunikasi, transportasi, riset operasi,dan sebagainya. Oleh karena itu, teori graf mengalami perkembangan yang begitu pesat.

Seiring perkembangan teori graf yang begitu pesat, muncul berbagai konsep baru, diantaranya yaitu dimensi metrik dari suatu graf yang diperkenalkan oleh Slater pada tahun 1975. Kemudian pada tahun 1976, Harary dan Melter secara independen juga memperkenalkan konsep yang sama. Misal $G$ adalah suatu graf terhubung nontrivial dengan himpunan vertex $V(G)$. Suatu himpunan $W \subset V(G)$ merupakan himpunan pembeda dari $G$ jika $d(u, x) \neq d(v, x)$ untuk sembarang vertex $u, v \in V(G)$ dan beberapa vertex $x \in W$, dimana $d(u, x)$ menyatakan jarak, yaitu panjang lintasan (path) terpendek dari vertex $u$ ke vertexx. Himpunan pembeda dengan kardinalitas terkecil disebut himpunan pembeda minimum atau basis dan banyaknya anggota pada basis disebut dimensi metrik. Hingga sekarang, telah muncul beberapa variasi dari himpunan 
pembeda, dan salah satunya yaitu himpunan pembeda lokal yang diperkenalkan oleh Okamoto et al. pada tahun 2010. Dimisalkan $W=\left\{w_{1}, w_{2}, \ldots, w_{k}\right\}$ merupakan himpunan bagian dari himpunan vertex pada graf $G$. Representasi suatu vertexu pada graf $G$ terhadap $W$ merupakan pasangan berurutan dari jarak vertexu dengan semua vertex di $W$. Jarak dua vertex pada graf $G$ didefinisikan sebagai panjang lintasan (path) terpendek dari satu vertex ke vertex lainnya. Himpunan $W$ disebut sebagai himpunan pembeda lokal jika representasi setiap dua vertex yang saling adjacent berbeda terhadap $W$. Himpunan pembeda lokal dengan jumlah anggota minimal disebut basis metrik lokal dan banyaknya anggota pada basis disebut dimensi metrik lokal.

Pada tahun 2016, Rodriguez-Velazquez et al. menentukan dimensi metrik lokal pada graf hasil operasi korona. Kemudian, pada tahun 2017 Cahyabudi dan Kusmayadi menentukan dimensi metrik lokal pada graf lollipop, graf web, dan graf friendship. Tahun 2018, Budianto dan Kusmayadi menentukan dimensi metrik lokal pada graf starbarbell, graf $K_{m} \odot P_{n}$, dan graf Möbius ladder. Pada tahun yang sama, Solekhah dan Kusmayadi menentukan dimensi metrik lokal pada graf $t$-fold wheel, graf $P_{n} \odot K_{m}$, dan graf generalized fan. Penelitian tersebut dapat digunakan sebagai acuan dalam menentukan dimensi metrik lokal pada kelas graf yang lain. Pada penelitian ini akan dibahas mengenai dimensi metrik lokal pada graf antiprisma dan graf sun.

\section{METODE PENELITIAN}

Metode penelitian yang digunakan dalam penelitian ini adalah kajian pustaka yaitu dengan mengumpulkan referensi berupa buku-buku dan jurnal. Dari metode ini, penulis dapat menentukan dimensi metrik lokal pada graf antiprisma dan graf sun.

Langkah-langkah yang dilakukan dalam penelitian ini diuraikan sebagai berikut.

1. Menentukan $W$ pada graf antiprisma dan graf sun.

2. Menghitung jarak setiap vertex dengan $W$ yang telah ditentukan, sedemikian sehingga setiap dua vertex berbeda yang saling adjacent pada graf antiprisma dan graf sun mempunyai representasi yang berbeda terhadap $W$.

3. Menentukan dimensi metrik lokal dan pola umum dimensi metrik lokal pada graf tersebut.

4. Membuat pembuktian dengan menyusun lema dan teorema berdasarkan hasil yang diperoleh.

5. Membuat kesimpulan. 


\section{HASIL DAN PEMBAHASAN}

Pada bab ini dibahas dimensi metrik lokal pada graf antiprismadan grafsun sehingga diperoleh rumus umum dan disertai pembuktiannya.

A. Dimensi Metrik Lokal Pada graf antiprisma

Menurut Bačaet al. graf antiprisma $A_{n}$ dengan $n \geq 3$ adalah suatu graf regular berdegree empat dengan jumlah vertex $2 n$ dan jumlah edge $4 n$. Tersusun atas $C_{n}$ luar dan dalam kemudian antara kedua cycle dihubungkan oleh edge $v_{i} u_{i}$ dan $v_{i} u_{i+i(\bmod n)}$ untuk $i=1,2,3, \ldots, n$.

Sebuah graf antiprisma $A_{n}$ dengan order $2 n$, size $4 n$, danhimpunan vertex $V\left(A_{n}\right)=\left\{u_{1}, u_{2}, \ldots, u_{n}, v_{1}, v_{2}, \ldots, v_{n}\right\}$ ditunjukkan pada Gambar 1.

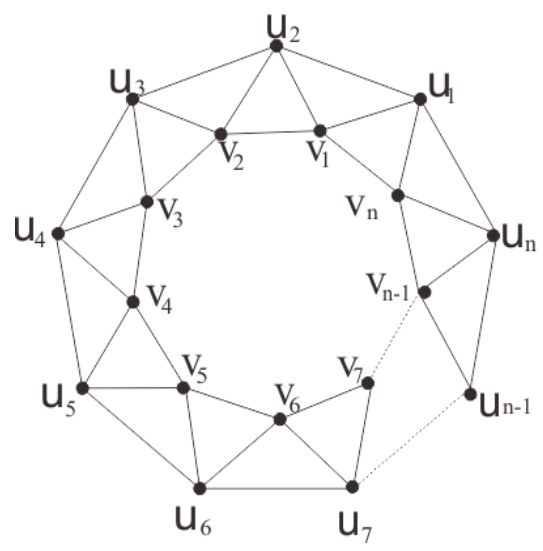

Gambar 1 Graf antiprisma $A_{n}$

Teorema 1.1.Jika $A_{n}$ merupakan graf antiprisma, maka dim $A_{n}=3$.

Bukti. Misal dipilih $W=\left\{u_{1}, u_{n}, v_{1}\right\}$ adalah himpunan pembeda lokal, diperoleh representasi setiap vertex terhadap $W$ untuk $n$ genap adalah

$$
\begin{aligned}
& r\left(u_{i} \mid W\right)=\left\{\begin{array}{cc}
(i-1, i, i), & 1 \leq i \leq \frac{n}{2} \\
(n-i+1, n-i, n-i+1), & \frac{n}{2}<i<n .
\end{array}\right. \\
& r\left(v_{i} \mid W\right)=\left\{\begin{array}{cc}
(1,1,0), & i=1 ; \\
(i-1, i, i-1), & 2 \leq i \leq \frac{n}{2} \\
(i-1, i-1, i-1), & i=\left\lceil\frac{n+1}{2}\right\rceil ; \\
\left(n-i+2, n-i+1, n_{i}+1\right), & \left\lceil\frac{n+1}{2}\right\rceil<i \leq n .
\end{array}\right.
\end{aligned}
$$

dan untuk $n$ ganjil adalah 


$$
\begin{gathered}
r\left(u_{i} \mid W\right)\left\{\begin{array}{cc}
(i-1, i, i), & 1 \leq i \leq\left\lfloor\frac{n}{2}\right\rceil ; \\
(i-1, i-1,1), & i=\left\lceil\frac{n}{2}\right\rceil ; \\
(n-i+1, n-i, n-i+1), & \left\lceil\frac{n}{2}\right\rceil<i \leq n .
\end{array}\right. \\
r\left(v_{i} \mid W\right)\left\{\begin{array}{cc}
(1,1,0), & i=1 ; \\
(i-1, i, i-1), & 2 \leq i \leq\left\lceil\frac{n}{2}\right\rceil ; \\
(i-1, i-2, i-2), & \left\lceil\frac{n}{2}\right\rceil \leq i \leq n .
\end{array}\right.
\end{gathered}
$$

Setiap vertex $V\left(A_{n}\right)$ memiliki representasi yang berbeda terhadap $W$, sehingga $W$ adalah himpunan pembeda lokal dengan tiga elemen. Selanjutnya ditunjukkan bahwa $A_{n}$ tidak memiliki himpunan pembeda lokal dengan 2 elemen.

Andaikan $A_{n}$ memiliki himpunan pembeda $W$ dengan 2 elemen, pemilihan vertex dari $W$ ada tiga kemungkinan

1. Kedua vertex dari $W$ termasuk dalam $\left\{u_{i}: 1 \leq i \leq n\right\} \subset V\left(A_{n}\right)$, misal diambil $W=\left(u_{1}, u_{2}\right)$ diperoleh $r\left(u_{n} \mid W\right)=r\left(v_{1}\right)=(1,2)$. Begitupun jika diambil sembarang dua vertex $u_{i} \in V\left(A_{n}\right)$ dengan $1 \leq i \leq n$ menjadi himpunan $W$, maka pasti akan terdapat dua vertex pada $A_{n}$ yang memiliki representasi sama terhadap $W$.

2. Kedua vertex dari $W$ termasuk dalam $\left\{v_{i}: 1 \leq i \leq n\right\} \subset V\left(A_{n}\right)$, misal diambil $W=\left(v_{1}, v_{2}\right)$ diperoleh $r\left(u_{1} \mid W\right)=r\left(v_{n}\right)=(1,2)$. Begitupun jika diambil sembarang dua vertex $v_{i} \in V\left(A_{n}\right)$ dengan $1 \leq i \leq n$ menjadi himpunan $W$, maka pasti akan terdapat dua vertex pada $A_{n}$ yang memiliki representasi sama terhadap $W$.

3. Salah satu vertex dari $W$ termasuk dalam $\left\{u_{i}: 1 \leq i \leq n\right\} \subset V\left(A_{n}\right)$ dan vertex lainnya termauk kedalam $\left\{v_{i}: 1 \leq i \leq n\right\} \subset V\left(A_{n}\right)$. Misal pada $A_{4}$ diambil $W=\left(v_{1}, u_{1}\right)$ diperoleh $r\left(u_{3} \mid W\right)=r\left(v_{3}\right)=(2,2)$. Begitupun juka diambil sembarang dua vertex dari $u_{i}, v_{i} \in V\left(A_{n}\right)$ dengan $1 \leq i \leq n$ menjadi himpunan $W$, maka pasti akan terdapat dua vertex pada $A_{n}$ yang memiliki representasi sama terhadap $W$.

Dari kemungkinan yang ada, diperoleh hasil yang kontradiksi dengan pengandaian. Oleh karena itu $A_{n}$ tidak memiliki himpunan pembeda lokal dengan dua elemen dan diperoleh bahwa himpunan pembeda lokal pada $A_{n}$ adalah tiga elemen, sehingga $\operatorname{dim}_{l} A_{n}=3$. 
B. Dimensi Metrik Lokal Pada Graf Sun

Menurut Mirzakhah dan Kiani. Graf sun adalah graf yang diperoleh dengan menambahkan satu pasangan vertex dan edge dari setiap vertex dalam suatu cycle. Misalkan graf sun $S_{n}$ mempunyai himpunan vertex $V\left(S_{n}\right)=\left\{v_{1}, v_{2}, \ldots, v_{n}, u_{1}, u_{2}, \ldots, u_{n}\right\} \quad$ dengan $n \geq 3$. Vertex-vertex $v_{1}, v_{2}, \ldots, v_{n}$ membentuk cycle dan vertex $v_{i}$ adjacent dengan vertex pada $u_{i}$, dimana $1 \leq i \leq n$. Bentuk umum graf sun dapat dilihat pada Gambar 2

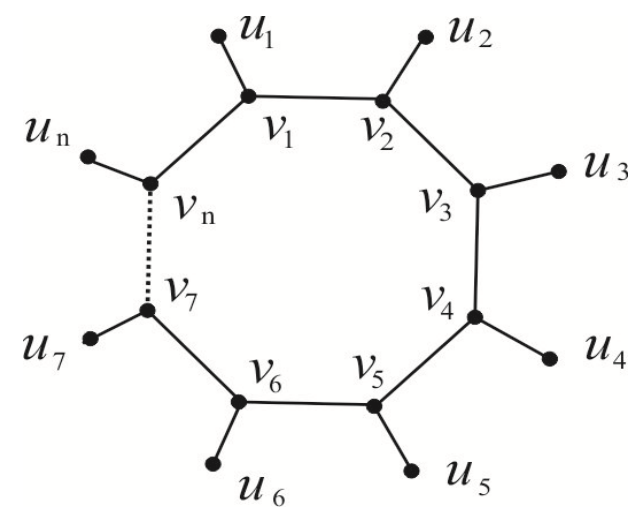

Gambar 2 Graf sun $\boldsymbol{S}_{\boldsymbol{n}}$

Berikut diberikan teorema dari Okamoto et al. yang digunakan untuk mendukung teorema selanjutnya.

Teorema 1.2.Diberikan graf $G$ adalah graf terhubung nontrivial ber-order $n$, maka $\operatorname{dim}_{l}(G)=n-1$ jika dan hanya jika $G=K_{n} \operatorname{dan}_{\operatorname{dim}}(G)=1$ jika dan hanya jika $G$ adalah graf bipartit.

Teorema 1.3.Jika $S_{n}$ adalah suatu graf sun dengan $n \geq 3$, maka dim $S_{n}$ adalah

$\{1, \quad$ untuk $n$ genap;

\{2, untuk $n$ ganjil.

Bukti. Diberikan graf sun $S_{n}$ dengan himpunan vertex $V\left(S_{n}\right)=\left\{v_{1}, v_{2}, \ldots, v_{n}, u_{1}, u_{2}, \ldots, u_{n}\right\}$. Dimensi mertik lokal pada graf sun terdiri atas dua kasus, yaitu untuk $n$ ganjil dan $n$ genap.

Kasus 1. Untuk $n$ genap

Misalkan himpunan vertex pada $S_{n}$ dipartisi menjadi dua himpunan vertex yaitu $V_{1}=\left\{v_{1}, v_{3}, v_{5}, \ldots, v_{n-1}, u_{2}, u_{4}, u_{6}, \ldots, u_{n}\right\}$

$\operatorname{dan} V_{1}=\left\{v_{2}, v_{4}, v_{6}, \ldots, v_{n}, u_{1}, u_{3}, u_{5}, \ldots, u_{n-1}\right\}$. Setiap vertex pada dua partisi tersebut tidak saling adjacent, yang berarti merupakan graf bipartit. Berdasarkan pada teorema 1.2. dapat disimpulkan bahwa $\operatorname{dim}_{l} S_{n}=1$ untuk $n$ genap.

Kasus 2. Untuk $n$ ganjil 
Misalkan dipilih $W=\left\{v_{\frac{n+1}{2}}, v_{1}\right\} \subset V\left(S_{n}\right)$, diperoleh representasi setiap vertex terhadap $W$ adalah

$$
\begin{aligned}
& r\left(u_{i} \mid W\right)\left\{\begin{array}{lc}
\left(\frac{n+1}{2}-i, i-1\right), & 1 \leq i \leq \frac{n+1}{2} \\
\left(\frac{n+1}{2}, n-i+2\right), & \frac{n+1}{2}<i \leq n .
\end{array}\right. \\
& r\left(v_{i} \mid W\right) \begin{cases}\left(\frac{n+3}{2}-i, i\right), & 1 \leq i \leq \frac{n+1}{2} ; \\
\left(\frac{n+1}{2}, n-i+2\right), & \frac{n+1}{2}<i \leq n .\end{cases}
\end{aligned}
$$

Karena setiap vertex yang saling adjacent pada $S_{n}$ memiliki representasi yang berbeda terhadap $W$ sehingga $W$ merupakan himpunan pembeda lokal dengan dua elemen. Berdasarkan pada teorema 1.2. yang menyatakan bahwa $\operatorname{dim}_{l}(G)=1$ jika dan hanya jika $G$ adalah graf bipartit, sedangkan graf $S_{n}$ dengan $n$ ganjil tidak dapat dipartisi menjadi dua himpunan vertex sehingga bukan merupakan graf bipartit oleh sebab itu, terbukti benar bahwa himpunan pembeda lokal pada graf $S_{n}$ adalah dua elemen, maka $\operatorname{dim}_{l}\left(S_{n}\right)=2$ untuk $n$ ganjil.

\section{SIMPULAN DAN SARAN}

Berdasarkan hasil dan pembahasan diperoleh kesimpulan sebagai berikut.

1. Dimensi metrik lokal pada graf antiprisma $A_{n}$ dengan $n \geq 3$ adalah $\operatorname{dim}_{l}\left(A_{n}\right)=3$.

2. Dimensi metrik lokal pada graf $\operatorname{sun} S_{n}$ dengan $n \geq 3$ adalah 1 untuk $n$ genap dan 2 untuk $n$ ganjil.

Penelitian ini membahas tentang dimensi metrik lokal pada graf antiprisma dan graf sun. Bagi pembaca yangtertarik dengan topik ini, dapat mengembangkan penelitian dengan menerapkannya pada kelas-kelas graf lain misalnya graf helm atau graf sunflower.

\section{DAFTAR PUSTAKA}

Bača, M., F. Bashir, and A. Semaničová. (2011). Face Antimagic Labeling of Antiprism. Util. Math, 84, 209-224.

Budianto, W.T., and T.A Kusmayadi. (2018). The Local Metric Dimension of starbarbell Graph, $K_{m} \odot P_{n}$ graph and Möbius Ladder graph, Journal of Physics: conference Series 1008012050.

Cahyabudi, A. N. and T. A. Kusmayadi. (2017).On The Local Metric Dimension of A Lollipop Graph, A Web Graph, and A Friendship Graph. Journal of Physics: Conference Series 909012039.

Chartrand, G., and L. Lesniak. (1979). Graphs and Digraphs, $2^{\text {nd }} e d$. California, Wadsworth Inc. 
Harary, F. and R. A. Melter (1976). On The Metric Dimension of A Graph. Ars Combinatoria 2, 191-195.

Mirzakhah, M. and D. Kiani. (2010). The Sun Graph is Determined by Its Signless Laplacian Spectrum. Electronic Journal of Linear Algebra 20, 610-620.

Okamoto, F., B. Phinezy, P. Zhang. (2010). The Local Metric Dimension of A Graph. Mathematica Bohemica 135(3), 239-255.

Rodr'iguez-Vel'azquez, J. A., G. A. Barrag'an-Ram'irez, and C. G. G'omez. (2016). On the Local Metric Dimension of Corona Product Graphs. Bull malays. Math. Sci. Soc. 39(2), 157-173.

Slater, P. J., Leaves of Trees. (1975). Congressus Numerantium 14, 549-559.

Solekhah, R.A., and T.A. Kusmayadi. (2017). On The Local Metric Dimension of t-Fold Wheel Graph, $P_{n} \odot K_{m}$ Graph, and Generalized Fan Graph. International Conference on Combinatoric, Graph Theory and Network Topology Universitas Negeri Jember. 